\title{
Assessment of the Willingness to Buy and the Use of Insecticide Treated Nets (ITN) among Caregivers of Under-Five Children Attending Immunization Clinics in a Private Tertiary Hospital in Plateau State, Nigeria
}

\author{
Lucy Idoko, Kingsley C. Okafor*, Gift M. Amlabu, Chidindu N. Idika, Blessing E. Oguche \\ Department of Community Medicine \& PHC, Bingham University, Karu, Nigeria \\ Email: ^drokaforkingsley@gmail.com
}

How to cite this paper: Idoko, L., Okafor, K.C., Amlabu, G.M., Idika, C.N. and Oguche, B.E. (2020) Assessment of the Willingness to Buy and the Use of Insecticide Treated Nets (ITN) among Caregivers of UnderFive Children Attending Immunization Clinics in a Private Tertiary Hospital in Plateau State, Nigeria. Advances in Infectious Diseases, 10, 90-110.

https://doi.org/10.4236/aid.2020.102008

Received: April 3, 2020

Accepted: May 8, 2020

Published: May 11, 2020

Copyright $\odot 2020$ by author(s) and Scientific Research Publishing Inc. This work is licensed under the Creative Commons Attribution International License (CC BY 4.0).

http://creativecommons.org/licenses/by/4.0/ (c) (i) Open Access

\begin{abstract}
Introduction: Malaria control becomes effective if countries adopt the World Health Organization \& Global Malaria Programme (WHO/GMP) recommendation with includes diagnosis of malaria cases and treatment with effective medicines, distribution of insecticide-treated nets (ITNs) and indoor residual spraying (IRS). Ownership and utilization of mosquito nets for malaria prevention is still sub-optimal with only $62 \%$ ownership of at least one mosquito net and only $37 \%$ of children using the nets. This seeks to investigate the willingness to buy and the use ITN use among caregivers of under five children attending immunization clinic in Bingham University Teaching Hospital. Methodology: A descriptive cross sectional study design carried out among 242 caregivers of all ages and sex of under-five children attending immunization clinic at Bingham University Teaching Hospital (BHUTH) in Jos North Local Government Area of Plateau State, Nigeria. A Simple Random Sampling technique was used to select respondents. Findings: Two hundred and sixteen $216(89.3 \%)$ of the children use ITNs, majority of the children $190(78.5 \%)$ slept under ITN the night before the interview, 226 (93.4\%) owned ITNs, 156 (64.5\%) got the ITNs for free while $60(24.8 \%)$ paid for it and majority 172 (71.1\%) of the children use ITN every night. Tertiary education, having much younger children (less than 3 years) and perception as a means of malaria prevention were associated with higher use of ITNs. Majority 220 (90.9\%) the caregivers were willing to buy ITN and also recommend ITN to others. Caregivers who were traders and civil servants were willing to buy ITN than farmers, tertiary education, having children $1-3$ months old, and owning 3 or
\end{abstract}


more ITNs was associated with willingness to buy ITNs. Conclusion: About $90 \%$ of the children of caregivers use ITNs and over three quarters slept under ITN the night before the interview and majority use it every night. Majority the caregivers were willing to buy ITN and also recommend ITN to others. The government and health care workers should continue to encourage and enlighten caregivers to keep using ITNs for their children and sustain mass free distribution of ITNs to improve ownership and utilization of ITNs.

\section{Keywords}

Insecticide Treated Nets, Willingness to Buy, Malaria

\section{Introduction}

Malaria remains a global burden contributing to morbidity and mortality especially in under-five children. The control of vector-borne diseases such as malaria is a major global health challenge of the $21^{\text {st }}$ century [1].

Malaria, a life threatening disease caused by plasmodium and transmitted by female anopheles mosquito is the second most common cause of infectious disease related deaths in the world [2] [3]. The case prevalence of malaria was 216 million and mortality of 445,000 worldwide with $90 \%$ and $91 \%$ respectively occurring in Africa and remains a public health problem in endemic areas [4] [5]. It is estimated that 1 out of every 20 children is likely to die from malaria-related illness before their fifth birthday in Sub-Saharan Africa [6] [7].

Nigeria accounts for $27 \%$ of the global malaria burden with under-five children and pregnant women most at risk [3]. It is implicated in approximately $60 \%$ of outpatient visits and $30 \%$ of admissions, with up to $25 \%$ of infant mortality and $30 \%$ of under-five mortality within the country [4] [8]. In Plateau State, a study carried out to quantify the prevalence and transmission patterns in the highlands and lowlands areas of Plateau State showed that the prevalence is $48.1 \%$ and it showed stable transmission [9]. In endemic areas or areas with stable transmission such as Plateau State, children under five are particularly prone to infection, illness and death as they lack acquired immunity accounting for the majority of malarial disease, particularly severe disease with rapid progression to death. This age group accounts for more than two-thirds (70\%) of all malaria deaths [10]. About 285,000 children in Africa died before their fifth birthdays [7]. Pregnant women are also at great risk of the most severe clinical symptoms of malaria because there is a temporary depression of immunity during pregnancy [11].

Malaria and poverty are strongly linked as poverty is associated with deprivation in terms of economic opportunities, access to services, health outcomes, education, skills and resources which can increase the risk of malaria [12] [13]. Poverty reduces the likelihood that households will adopt appropriate preven- 
tive measures (such as sleeping under insecticide-treated nets [ITNs]) and curative measures (seeking timely health care for fevers) and conversely, malaria might further impoverish poorer households through the costs of preventive and curative measures, as well as for the inability to work while ill [11] [14] [15].

Using mosquito nets as a protection against insects was practiced in historical times especially during World War II (1939-1945), Russian, German and United States armies treated bed nets to protect soldiers against vector-borne diseases [16]. Ownership and utilization of mosquito nets for malaria prevention is still sub-optimal with only 62 percent ownership of at least one mosquito net and only 37 percent of children using the nets [17]. The WHO Global Malaria Programme (WHO/GMP) recommends 3 primary interventions for effective malaria control which includes; diagnosis of malaria cases and treatment with effective medicines, distribution of insecticide-treated nets (ITNs), indoor residual spraying (IRS) [2] [3].

ITN function in three main ways: first they act as a physical barrier to preventing access of mosquitoes thus, providing personal protection against malaria to the individual(s) using the nets. Secondly, the chemical in ITNs repels the mosquitoes or kills them when they come in contact with it. Thirdly, it reduces the overall mosquito population in the community when majority of the community sleep under an ITN [4] [6] [18]. The use of ITNs is one of the cheapest and most effective interventions against malaria [4] [17] [19]. World Health Organization recommends 3 kinds of ITNs namely: Permethrin-incorporated nets, Deltamethrin-coated nets and Alphacypermethrin-coated nets [20] [21]. Insecticide Treated Nets (ITN) were introduced in Nigeria as an effective means of preventing mosquito bite and malaria transmission following a meeting in Abuja, Nigeria of Africa Heads of States in the year 2000 [22]. With the levels of resistance to drugs by malaria parasite and the resistance of mosquitoes that transmit malaria to insecticide coupled with the absence of effective vaccine for malaria prevention, malaria prevention through the use of ITNs remains a very important strategy for malaria control [4]. The use of ITNs is the main method of malaria control in Nigeria [4] [8].

The WHO recommended that all health ministries and donor agencies scale up the distribution of ITNs, specifically to populations of children under-five of age and pregnant women [21]. Most national malaria control programs have adopted universal coverage of ITN distribution and incorporated mass distribution campaigns of ITNs. Out of 663 million malaria cases, averted in the past 15 years in sub-Saharan Africa, $63 \%-73 \%$ has been attributed to the extensive distribution of ITNs [2]. ITNs have been shown to reduce severe disease due to malaria and mortality (by 20\%) in endemic regions [23]. The provision of insecticide-treated nets was a key strategy in successful malaria elimination programs in some countries, in Sri Lanka, ninety-one percent of these nets in households were obtained from free distribution programmes, $69 \%$ of households in Sri 
Lanka possess at least one mosquito net and usage by under-fives stands at seventy-one percent. By 2006, the country recorded less than 1000 cases per year and since October 2012, the indigenous cases were down to zero [2] [20] [24]. There is still a lot of work to be done to meet the $75 \%$ target for reduction in mortality and incidence of malaria globally as set in the global technical strategy for malaria of the World Health Organization [21].

Perceived malaria risk increases the likelihood of ownership and use of ITN with a mean of 1.33 nets in households with children aged 0 to 4 years as against 1.14 nets in households with children aged 10 to 14 years [25]. Other determinants of use of ITNs include occupation [26] [27] age of caregivers [28] [29] season of the year [30] and living close to a health institution [31].

The most important determining factor of ITN usage is ownership [23]. Insecticide-treated nets reduce child mortality from all causes by $17 \%$ compared to no nets (rate ratio $0.83,95 \%$ CI 0.77 to 0.89 ) [32]. This study is of importance as it seeks to investigate the willingness to buy and willingness to use ITN use among caregivers of under five children attending immunization clinic in Bingham University Teaching Hospital. Given the fact that use of ITN is critical to the reduction of Malaria burden, and the inadequate level of use among communities, there is need to find out factors associated with increased utilization of ITN in Nigeria. The objective of this study is to determine the proportion of caregivers whose children are sleeping under ITNs, identify factors affecting use of ITNs and determine the proportion of caregivers willing to buy ITNs.

\section{Methodology}

The study was carried out at Bingham University Teaching Hospital (BHUTH), 250 bed spaced, faith based tertiary health institution located in Jos North Local Government Area of Plateau State, Plateau State. It is owned by the Evangelical Church Winning All (ECWA). Participants were recruited at the Immunization clinic, in the department of Paediatrics. The clinic provides routine immunization for underfive children, breastfeeding and nutritional counselling for caregivers of the children. The clinic runs on Wednesdays with an average of 50 under-five children attending weekly. The study involved all caregivers of all ages and sex of under five children attending immunization clinic at BHUTH from August to November, 2018. The study excluded children whose caregivers declined consent and those who were ill and referred out of the clinic. A descriptive cross sectional study design was used in conducting this study. It utilized an interviewer administered structured questionnaire.

Sample Size was determined using the Cochran's formula [33].

$$
n=z^{2} p q / d^{2}
$$

where $p=$ proportion of under-fives who slept under ITN the previous night in North-central geopolitical zone in a study done from Nigeria malaria indicator survey $-59.7 \%$ [4]. The calculated minimum sample size was 370 and $10 \%$ of the minimum sample size was added to the sample size to give room for errors to 
achieve a sample size of 407.

A Simple Random Sampling technique was used to select participants. A list of registered caregivers who attending immunization session was used as the sampling frame, selection was done by balloting.

The data was collected from caregivers of under-five children attending immunization clinic using a structured interviewer-administered questionnaire. Data collected includes use of ITN and reasons for not using ITN, ownership, number, type \& source of mosquito net in their homes, duration, frequency, and time of the year of use of ITN. Caregivers off label use, dipping in water, and sun drying of ITNs since purchase, caregivers willingness to buy ITN. At the end of the data collection period, 242 participants were interviewed. A response rate of 65.4\% was achieved. Ethical clearance was obtained from the Ethical Review Committee of BHUTH, Jos. Study limitation include the interviewers did not go to the houses of the respondents to see their ITNs or observe the children sleeping under ITNs; it was based on self report. The completed questionnaires were analysed using Statistical Package for the Social Science (SPSS) version 20. Statistical significance was determined using chi square. A 95\% confidence interval was used for the study and $\mathrm{P}$ value $<0.05$ was considered statistically significant in bivariate analyses.

\section{Results}

1) Under-five children that use ITN, 24 hour recall and reasons for non-ITN by of caregivers

Table 1 shows that $216(89.3 \%)$ of the children use ITNs while $26(10.7 \%)$ had not used ITN.

Majority of the children 190 (78.5\%) slept under ITN the night before the interview while $52(21.5 \%)$ did not sleep under ITN the night before the interview.

On reasons for not using ITNs, 3 (11.5\%) of the caregivers do not use ITNs because they feel that ITNs are suffocating, 3 (11.5\%) have an unpleasant smell, $5(19.3 \%)$ of them say that ITN use is inconveniencing and another $5(19.3 \%)$ do not use ITNs for their children because their mother did not use it, 1 (3.8\%) feel it is not necessary, $1(3.8 \%)$ cannot disclose, $2(7.8 \%)$ say doors are not left open, $3(11.5 \%)$ said they do not feel like using it, $3(11.5 \%)$ did not give any reason.

2) Ownership, number, type \& source of Mosquito Net in Their Houses

Table 2 shows that 226 (93.4\%) owned ITNs, Of these, 226 (93.4\%) of mosquito nets possessed by caregivers were ITNs while untreated bed nets made up $1(0.4 \%), 13$ (5.4\%) of the caregivers had no mosquito net.

Ninety (37.2\%) caregivers had more than 3 ITNs, 72 (29.8\%) had two ITNs, 64 (26.4\%) had one, while 16 (6.6\%) had none.

$156(64.5 \%)$ got the ITNs for free while $60(24.8 \%)$ paid for it. A higher proportion of ITNs owned by caregivers were gotten free, either from the clinic 61 (25.2\%) or elsewhere outside the hospital 79 (32.7\%) respectively while 10 (4.1\%) were bought from a chemist. 
Table 1. Distribution of under-five children that use ITN and reasons for Non-ITN by of Caregivers.

Number of caregivers

Percentage (\%)

Currently using ITNs $(\mathrm{n}=242)$

$\begin{array}{lcc}\text { Yes } & 216 & 89.3 \\ \text { No } & 26 & 10.7\end{array}$

Under 5 that slept under ITN the previous night $(24 \mathrm{hr}$ recall $)(\mathrm{n}=242)$

$\begin{array}{lcc}\text { Yes } & 190 & 78.5 \\ \text { No } & 52 & 21.5\end{array}$

Reasons for not using -ITN $(\mathrm{n}=26)$

$\begin{array}{ccc}\text { Nets are suffocating } & 3 & 11.5 \\ \text { Chemical smells } & 3 & 11.5 \\ \text { Inconvenience } & 5 & 19.3 \\ \text { Not necessary } & 1 & 3.8 \\ \text { Mother does not use it } & 5 & 19.3 \\ \text { Cannot disclose } & 1 & 3.8 \\ \text { Doors are not left open } & 2 & 7.8 \\ \text { Do not feel like } & 3 & 11.5 \\ \text { Do not know } & 3 & 11.5\end{array}$

Table 2. Ownership, number, type \& source of mosquito net in their houses.

\begin{tabular}{ccc}
\hline Ownership of ITN & Number of caregivers & Percentage (\%) \\
Yes & 226 & 93.4 \\
No & 16 & 6.6 \\
Number of ITNs owned by households & 16 & 6.6 \\
None & 64 & 26.4 \\
One & 72 & 29.8 \\
Two & 90 & 37.2 \\
Three and above & & \\
Type of mosquito net available & 13 & 5.4 \\
None & 2 & 0.8 \\
Window net & 1 & 0.4 \\
Untreated bed net & 226 & 93.4 \\
ITN & & 64.5 \\
Paid for ITNs & 156 & 24.8 \\
No (Got for free) & 60 & 10.7 \\
Yes (Paid for ITN) & 26 & \\
Not applicable & & \\
\hline
\end{tabular}




\begin{tabular}{ccc}
\hline Source of ITN & 79 & \\
Free outside the hospital & 61 & 32.7 \\
Free from the hospital & 50 & 25.2 \\
Bought from the market & 16 & 20.7 \\
Free from family and friends & 10 & 6.6 \\
Bought from the chemist & 26 & 4.1 \\
Not applicable & 242 & 10.7 \\
Total & & 100.0 \\
\hline
\end{tabular}

\section{3) Duration, frequency, time of the year of use of ITN}

Table 3 shows that 36 (14.9\%) had used their ITNs for less than 6 months, 66 (27.3\%) had used their ITNs for 6 - 12 months, 51 (21.1\%) had use it for 13 - 24 months, 19 (7.8\%) had used theirs for 25 - 36 months, while 44 (18.2\%) had use their own for more than 36 months.

Majority $172(71.1 \%)$ of the children use ITN every night, $44(18.2 \%)$ use it occasionally, while 26 (10.7\%) had never used ITN.

A higher proportion 166 (68.6\%) of the children use ITN all year round, 24 $(9.9 \%)$ use ITN only during rainy season, $6(2.5 \%)$ use ITN only during dry season, $8(3.3 \%)$ use it any time they feel like, $6(2.5 \%)$ use ITNs only if there are mosquitoes, while 6 (2.5\%) could not tell.

4) Caregivers off label use, dipping in water, an sun drying of ITNs since purchase

Table 4 shows that $49.6 \%$ of the caregivers had either dipped their ITN in liquid or spread under the sun while $39.7 \%$ had never done any.

Majority of the caregivers $212(87.7 \%)$ had used their ITNs for nothing else however $2(0.8 \%)$ had used their ITNs to cover seedlings, $1(0.4 \%)$ for fishing and $1(0.4 \%)$ had used their ITNs as screen at backyard.

5) Association between Use of ITN and education, age of caregiver, and occupation of caregiver

Table 5 shows a higher proportion of care givers 140 (57.9\%) with tertiary education use ITN while a few $2(0.8 \%)$ with no education or primary education $2(1.2 \%)$ use ITN. This finding is statistically significant (Fischers $=12.78, \mathrm{p}=$ $0.0495)$.

There was no statistically significant association between Use of ITN and Age of Caregiver (Fischers $=45.922, \mathrm{p}=0.1012$ ). Also, there was no statistically significant association between use of ITN and occupation of caregiver (Fischer's = 13.906, $\mathrm{p}=0.6218$ ).

More Care givers with children within the age 1 - 3 years $88(36.4 \%)$ used ITN, while 7 (7.9\%) who used ITN were agd 7 - 9 years. This finding was statistically significant (Fischer $=21.874, \mathrm{p}=0.0042$ ).

A higher proportion of households with 1 under five 89 (36.8\%) used ITN 
Table 3. Duration, frequency, time of the year of use of ITN.

\begin{tabular}{|c|c|c|}
\hline Duration of use of ITN & Number of caregivers & Percentage (\%) \\
\hline$<6$ months & 36 & 14.9 \\
\hline $6-12$ months & 66 & 27.3 \\
\hline 13 - 24 months & 51 & 21.1 \\
\hline 25 - 36 months & 19 & 7.8 \\
\hline$>36$ months & 44 & 18.2 \\
\hline Not applicable & 26 & 10.7 \\
\hline \multicolumn{3}{|l|}{ Frequency of use of ITN } \\
\hline Every night & 172 & 71.1 \\
\hline Occasionally & 44 & 18.2 \\
\hline Never & 26 & 10.7 \\
\hline \multicolumn{3}{|l|}{ Time of year } \\
\hline All year round & 166 & 68.6 \\
\hline During rainy season & 24 & 9.9 \\
\hline During dry season & 6 & 2.5 \\
\hline Any time they feel like & 8 & 3.3 \\
\hline Only if there are mosquitoes & 6 & 2.5 \\
\hline Cannot tell & 6 & 2.5 \\
\hline Not applicable & 26 & 10.7 \\
\hline Total & 242 & 100.0 \\
\hline
\end{tabular}

Table 4. Distribution of Caregivers off label use, dipping in water, an sun drying of ITNs since purchase.

\begin{tabular}{ccc}
\hline ITN dipped in water & Number of caregivers & Percentage (\%) \\
\hline Yes & 120 & 49.6 \\
No & 96 & 39.7 \\
Not applicable & 26 & 10.7 \\
ITN spread in the sun & 120 & 49.6 \\
Yes & 96 & 39.7 \\
No & 26 & 10.7 \\
Not applicable & & \\
Off label use of ITN & 2 & 0.8 \\
Cover for seedlings & 1 & 0.4 \\
Fishing & 1 & 0.4 \\
Screen at backyard & 212 & 87.7 \\
Nothing else & 26 & 10.7 \\
Not applicable & 242 & 100.0 \\
Total & & \\
\hline
\end{tabular}


Table 5. Association between Use of ITN and education, age of caregiver, and occupation of caregiver.

\begin{tabular}{|c|c|c|c|c|c|}
\hline & \multicolumn{2}{|c|}{ ITN use } & \multirow{2}{*}{ Total } & \multirow{2}{*}{ Test statistics } & \multirow{2}{*}{$P$ value } \\
\hline & Yes & No & & & \\
\hline \multicolumn{6}{|c|}{ Caregivers level of education } \\
\hline None & $2(0.8)$ & $0(0.0)$ & $2(0.8)$ & \multirow{4}{*}{ Fishers $=12.78$} & \multirow{4}{*}{$\mathrm{P}=0.0495$} \\
\hline Primary & $3(1.2)$ & $1(0.4)$ & $4(1.7)$ & & \\
\hline Secondary & $71(29.3)$ & $10(4.1)$ & $81(33.5)$ & & \\
\hline Tertiary & $140(57.9)$ & $15(6.2)$ & $155(64.0)$ & & \\
\hline \multicolumn{6}{|c|}{ Age of caregiver (years) } \\
\hline$\leq 19$ & $3(1.2)$ & $0(0.0)$ & $3(1.2)$ & \multirow{6}{*}{ Fishers $=45.922$} & \multirow{6}{*}{$P=0.1012$} \\
\hline $20-24$ & $16(6.6)$ & $4(1.7)$ & $8.3(20.0)$ & & \\
\hline $25-29$ & $65(26.9)$ & $14(5.8)$ & $79(32.6)$ & & \\
\hline $30-34$ & $77(31.8)$ & $5(2.1)$ & $82(33.9)$ & & \\
\hline $35-39$ & $48(19.8)$ & $2(0.8)$ & $50(20.7)$ & & \\
\hline$\geq 40$ & $7(2.9)$ & $1(0.4)$ & $8(3.3)$ & & \\
\hline \multicolumn{6}{|c|}{ Occupation of caregiver } \\
\hline Trader & $77(31.8)$ & $5(2.1)$ & $82(33.9)$ & \multirow{9}{*}{ Fishers $=13.906$} & \multirow{9}{*}{$P=0.6218$} \\
\hline Unemployed & $57(23.6)$ & $8(3.3)$ & $65(26.9)$ & & \\
\hline Civil servant & $36(14.9)$ & $2(0.8)$ & $38(15.7)$ & & \\
\hline Teacher & $21(8.7)$ & $3(1.2)$ & $24(9.9)$ & & \\
\hline Artisan & $13(5.4)$ & $3(1.2)$ & $16(6.6)$ & & \\
\hline It expert & $3(1.2)$ & $0(0.0)$ & $3(1.2)$ & & \\
\hline Missionary & $2(0.8)$ & $2(0.8)$ & $3(1.7)$ & & \\
\hline Farmer & $2(0.8)$ & $1(0.4)$ & $3(1.2)$ & & \\
\hline${ }^{* *}$ others & $5(2.1)$ & $2(0.8)$ & $7(2.9)$ & & \\
\hline \multicolumn{6}{|c|}{ Age of child (Months) } \\
\hline$<1$ & $7(2.9)$ & $1(0.4)$ & $8(3.3)$ & \multirow{10}{*}{ Fishers $=21.874$} & \multirow{10}{*}{$\mathrm{P}=0.0042$} \\
\hline $1-3$ & $88(36.4)$ & $16(6.6)$ & $104(43.0)$ & & \\
\hline $4-6$ & $40(16.5)$ & $3(1.2)$ & $33(17.8)$ & & \\
\hline $7-9$ & $31(12.8)$ & $2(0.8)$ & $33(13.6)$ & & \\
\hline $10-12$ & $7(2.9)$ & $0(0.0)$ & $7(2.9)$ & & \\
\hline $13-15$ & $19(7.9)$ & $1(0.4)$ & $20(8.3)$ & & \\
\hline $16-18$ & $11(4.5)$ & $3(1.2)$ & $14(5.8)$ & & \\
\hline $19-21$ & $3(1.2)$ & $0(0.0)$ & $3(1.2)$ & & \\
\hline $22-24$ & $7(2.9)$ & $0(0.0)$ & $7(2.9)$ & & \\
\hline$>24$ & $3(1.2)$ & $0(0.0)$ & $3(1.2)$ & & \\
\hline
\end{tabular}




\section{Continued}

Nos of under-5 in household

\begin{tabular}{|c|c|c|c|c|c|}
\hline 1 & 89 (36.8) & $15(6.2)$ & $104(43.0)$ & & \\
\hline 2 & $116(47.9)$ & $8(3.3)$ & $124(51.2)$ & & \\
\hline 3 & $11(4.5)$ & $2(0.8)$ & $13(5.4)$ & Fishers $=43.165$ & $P=0.006$ \\
\hline & $0(0.0)$ & $1(0.4)$ & $1(0.4)$ & & \\
\hline
\end{tabular}

Nos of rooms in house

\begin{tabular}{|c|c|c|c|c|c|}
\hline $1-3$ & $49(20.2)$ & $9(3.7)$ & $58(24.0)$ & & \\
\hline $4-6$ & $137(56.6)$ & $13(5.4)$ & $150(62.0)$ & $x^{2}=7.427$ & $\mathrm{P}=0.3471$ \\
\hline $7-9$ & $19(7.9)$ & $3(1.2)$ & $22(9.1)$ & & \\
\hline$\geq 10$ & $11(4.5)$ & $1(0.4)$ & $12(4.9)$ & & \\
\hline Total & $216(89.3)$ & $26(10.7)$ & $242(100.0)$ & & \\
\hline
\end{tabular}

${ }^{*}$ Others include: Editor (2), Receptionist (2), Event management (2), literacy consultant (1).

while 11 (4.5\%) households with three under fives used ITN. This finding was statistically significant (Fischers $43.165, \mathrm{p}=0.006$ ). There was no statistically significant association between the use of ITN and number of room in the house $\left(\chi^{2}=7.427, \mathrm{p}=0.3471\right)$.

\section{6) ITN Use by Perception of ITN as a Means of Malaria Prevention}

Table 6 shows that most of caregivers who perceived ITN as a means of Malaria prevention used ITNs, 205 (86.1\%). This finding was statistically significant $\left(\chi^{2}=23.716, \mathrm{p}=0.0017\right)$.

\section{7) Caregivers willingness to buy\& recommend ITN to other caregivers}

Table 7 shows that majority of caregivers, 220 (90.9\%) were willing to buy ITN however, 22 (9.1\%) were not (Figure 1). Also, majority of the caregivers 220 (90.9\%) were willing to recommend ITN to others while 22 (9.1\%) were not. One hundred and thirty caregivers 130 (53.7\%) preferred to buy ITN over other things while fewer, $112(46.3 \%)$ preferred to buy other things over ITN.

Two hundred and sixteen caregivers $(89.3 \%)$ are using ITNs for their under 5 children, while 26 (10.7\%) are not using ITNs for their under five children.

8) Association between Willingness to Buy ITN, Occupation, level of education and age of child of Caregiver.

Table 8 shows that more caregivers who were traders 75 (31.0\%) and civil servants $36(14.9 \%)$, were willing to buy ITN than farmers $3(1.2 \%)$. This finding was statistically significant.

More caregivers with tertiary education (made up 143 (59.1\%) of caregivers) were willing to buy ITN, while a lower proportion of caregivers with primary education made up 4 (1.7\%). More caregivers with education where willing to buy ITNs, this finding was statistically significant $(p=0.003$, Fishers $=7.43$ ).

Also, more caregivers with children 1 - 3 months old, 97 (40.1\%) of were willing to buy ITNs than those with children 22 - 24 months, 6 (2.5\%) This findings were statistically significant, Fishers $=18.71, \mathrm{P}=0.0292$. 
Table 6. Distribution of ITN Use by Perception of ITN as a Means of Malaria Prevention.

\begin{tabular}{cccccc}
\hline \multirow{2}{*}{$\begin{array}{c}\text { Perception of ITN as a means } \\
\text { of malaria prevention }\end{array}$} & \multicolumn{2}{c}{ ITN use } & Total & Test Statistic & P value \\
\cline { 2 - 3 } & Yes & No & & & \\
\hline Yes & $205(86.1)$ & $25(10.5)$ & $230(96.6)$ & & \\
No & $7(2.9)$ & $1(0.4)$ & $8(3.4)$ & $\chi^{2}=23.716$ & 0.0017 \\
Total & $216(89.1)$ & $26(10.9)$ & $238(100.0)$ & & \\
\hline
\end{tabular}

Table 7. Distribution of Caregivers willingness to buy ITN \& currently using.

\begin{tabular}{cccc}
\hline & Yes (\%) & No (\%) & Total (\%) \\
\hline Willingness to buy ITN & $220(90.9)$ & $22(9.1)$ & $242(100.0)$ \\
Currently using ITN & $216(89.3)$ & $26(10.7)$ & $242(100.0)$ \\
Willingness to recommend ITN to other caregivers & $220(90.9)$ & $22(9.1)$ & $242(100.0)$ \\
$\begin{array}{c}\text { Preference to purchase other things instead of ITN } \\
\text { P }\end{array}$ & $112(46.3)$ & $130(53.7)$ & $242(100.0)$ \\
\hline
\end{tabular}

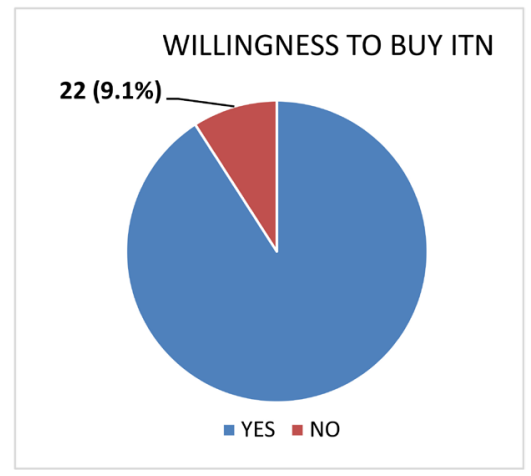

Figure 1. Willingness of caregivers to buy Insecticide treated nets.

Table 8. Association between Willingness to Buy ITN, Occupation, level of education and age of child of Caregiver.

\begin{tabular}{cccccc}
\hline & \multicolumn{2}{l}{ Willingness to buy ITN } & Total & Test statistics & P value \\
\cline { 2 - 3 } & Yes & No & & \\
\hline Occupation of caregiver & & & & & \\
Trader & $75(31.0)$ & $7(2.9)$ & $82(33.9)$ & & \\
Unemployed & $59(24.4)$ & $6(2.5)$ & $65(26.9)$ & & \\
Civil servant & $36(14.9)$ & $2(0.8)$ & $38(15.7)$ & & \\
Teacher & $23(9.5)$ & $1(0.4)$ & $24(9.9)$ & & \\
Artisan & $11(4.5)$ & $5(2.1)$ & $16(6.6)$ & & \\
Missionary & $3(1.2)$ & $1(0.4)$ & $4(1.7)$ & & \\
Farmer & $3(1.2)$ & $0(0.0)$ & $3(1.2)$ & & \\
IT expert & $3(1.2)$ & $0(0.0)$ & $3(1.2)$ & & \\
$* *$ others & $7(2.9)$ & $0(0.0)$ & $7(2.9)$ & & \\
Total & $220(90.9)$ & $22(9.1)$ & $242(100.0)$ & & \\
& & & &
\end{tabular}




\section{Continued}

\begin{tabular}{cccc}
\hline Level of education & & & \\
None & $2(0.8)$ & $0(0.0)$ & $2(0.8)$ \\
Primary & $4(1.7)$ & $0(0.0)$ & $4(1.7)$ \\
Secondary & $71(29.3)$ & $10(4.1)$ & $81(33.5) \quad$ Fishers $=7 . .23 \quad$ P $=0.003$ \\
Tertiary & $143(59.1)$ & $12(5.0)$ & $155(64.0)$ \\
Total & $220(90.9)$ & $22(9.1)$ & $242(100.0)$ \\
Age of child (months) & & & \\
$<1$ & $8(3.3)$ & $0(0.0)$ & $8(3.3)$ \\
$1-3$ & $97(40.1)$ & $7(2.9)$ & $104(43.0)$ \\
$4-6$ & $37(15.3)$ & $6(2.5)$ & $43(17.8)$ \\
$7-9$ & $31(12.8)$ & $2(0.8)$ & $33(13.6)$ \\
$10-12$ & $5(2.1)$ & $2(0.8)$ & $7(2.9)$ \\
$13-15$ & $19(7.9)$ & $1(0.4)$ & $20(8.3) \quad$ Fishers = $18.71 \quad$ P = 0.0292 \\
$16-18$ & $13(5.4)$ & $1(0.4)$ & $14(5.8)$ \\
$19-21$ & $1(0.4)$ & $2(0.8)$ & $3(1.2)$ \\
$22-24$ & $6(2.5)$ & $1(0.4)$ & $7(2.9)$ \\
$>24$ & $3(1.2)$ & $0(0.0)$ & $3(1.2)$ \\
Total & $220(90.9)$ & $22(9.1)$ & $242(100)$
\end{tabular}

${ }^{* *}$ Others include: Editor (2), Receptionist (2), Event management (2), literacy consultant (1).

Table 9. Distribution of willingness to buy ITN by Number of ITN owned.

\begin{tabular}{cccccc}
\hline \multirow{2}{*}{$\begin{array}{c}\text { Number of ITNs in } \\
\text { household }\end{array}$} & \multicolumn{2}{c}{ Willingness to buy ITNs } & Total & Test Statistic & P value \\
\cline { 2 - 3 } None & $11(4.7)$ & $49(1.7)$ & $15(6.4)$ & & \\
One & $49(21.0)$ & $5(2.1)$ & $54(23.2)$ & & \\
Two & $68(29.2)$ & $4(1.7)$ & $72(30.9)$ & $\chi^{2}=11.208$ & $\mathrm{p}=0.008$ \\
Three and above & $89(38.2)$ & $3(1.3)$ & $92(39.5)$ & & \\
Total & $217(93.1)$ & $16(6.9)$ & $233(100.0)$ & & \\
\hline
\end{tabular}

\section{9) Willingness to Buy ITN by Number of ITN Owned}

Table 9 shows that more 89 (38.2\%) caregivers who had three or more ITNs where willing to buy ITNs while only 11 (4.7\%) of caregivers without ITNs where willing to buy ITNs for their children. This finding as statistically significant $\left(\chi^{2}=11.208, \mathrm{p}=0.008\right)$.

\section{Discussion}

Nine in ten children used insecticide treated nets (ITN), from which three quarters slept under ITN a night before the interview. This finding is much higher than a studies done in Ekiti State (50\%) [22], Abakaliki [23] (52.4\%), Imo State, 
[34] South Eastern Nigeria (53\%), Calabar [35] (55.6\%), Tanzania [36] (56\%), Northern part of Lagos State [37] (61.8\%), Ogun State [38] (66\%), Southwestern Uganda. (66.1\%) [39], Ghana (66\%) [40]. This disparity may be due to the fact that the mothers in Plateau State had exposure to campaigns and distribution of ITNs in the past. Much lower percentages were observed in Nkanu, Enugu State (20\%) [41], a hospital based study in UNTH, Enugu [42] (26.1\%), Volta region of Ghana [43] (41\%), in Ashanti, Greater Accra, and Western regions in Ghana [44] (30.7\%), Osun State [18] (32.8\%) and Kenya [45] with a percentage use of $36.6 \%$. This low use of ITNs presents a huge risk to these communities while the high utilization of ITNs among respondents in the current study demonstrates a positive public health attribute. These findings are similar to finding in the $\mathrm{Na}$ tional Malaria Indicator Survey [4] where plateau has a 78\% use of ITNs while other geopolitical zones show are as follows North Central (55\%), North East (80\%), North West (91\%) South East (64\%) South South (64\%) and South West (53\%). The NDHS 2018 also revealed that the use of ITNs among children under age 5 has increased over the past 10 years, from 5\% in 2008 to $52 \%$ in 2018 [8].

Generally, the percentage of under five children who slept under an ITN the previous night has steadily increased from $5 \%$ in 2008, 16\% in 2010, 34\% in 2013 and $49 \%$ in 2015 [10].

This progress is reflected in the findings from this study where over three quarters of the children slept under ITN the night before the interview. This trend is also shown in a study done in Ibadan [46] where over a quarter slept under the ITN the night before the interview. This is contrast to studies done in Calabar [35] where about a quarter slept under the ITN the night before the interview. This study showed 79\% of underfive children from this study slept under ITN the previous night, this is below the World Health Assembly target of $80 \%$. However, this is above the World Malaria Report that estimates that 54\% of children in sub-Saharan Africa sleep under it [3]. Data obtained from Nigeria Malaria Indicator Survey put National figures at $44 \%$ while North Central is $39 \%$ [4]. A study in Ogun State reported that $29 \%$ of under five children slept under ITN the previous night [38].

ITNs were not used by caregiver for their children because they complained about suffocation, unpleasant smell, some said it was inconveniencing, Others said their mother did not use it, they do not feel it is necessary, say doors are not left open, said they do not feel like using it. Similar reason were given in a study done in Imo State [34], Abia [47] and Abakaliki [22] these reasons will usually lead to non use of ITNs in the households. Thus, it is important to ensure behavioural change towards use of ITNs, especially as these reasons for non use are marginal when compared to the mortality and morbidity associated with Malaria. This study showed that $19 \%$ identified inconvenience as reason for non-use as observed in other studies in Lake Victoria [48], 12\% mentioned that sleeping under ITN caused suffocation. Other reasons were bad odour from nets, doors are not left open as noted in a study by Ezeama et al. (2014). Some other care- 
givers said they did not feel like using ITNs for their children which is similar to findings in another study in Eastern Nigeria [49]. Other studies reported [50] itching and "do not work" as reasons for non-use. Other studies in Sub Saharan Africa [51] have cited problems with hanging up nets and lack of space as reasons for non-use.

Ownership of ITNs has always shown a rise over the past 10 years, increasing from $8 \%$ in the 2008 NDHS to $69 \%$ in the 2015 NMIS, sadly, ownership of ITNs dropped to $61 \%$ in 2018. [8] This drop was not demonstrated in this study where 94\% owned ITNs. Other studies [52] have shown that $97 \%$ of households in Akwa Ibom State had ITNs, $79 \%$ had in Kebbi while $62 \%$ owned ITNs in Nasarawa State [52]. Of these, over a third of the caregivers had more than 3 ITNs, about a third had two ITNs, and a quarter had one. This finding is higher than the NDHS 2018 survey whch found out that $61 \%$ of households own at least one insecticide-treated net (ITN) [8]. This high proportion of ownership was found in studies done in Volta region of Ghana where $80 \%$ had ITNs [43], in Ethiopia 72.4\% owned ITNs [53], in Kenya [45] 73.8\% had ITNs, $84.0 \%$ had ITNs in Southwestern Uganda [39] 71.5\% in Calabar [35], While Abakaliki [23] had $81.2 \%$ of the subjects owning at least one ITN in their homes. A study done in Ibadan, Oyo State [46] (11.1\%) and Abia State [47] had a much lower value (38.6\%). The National Malaria Indicator Survey. [4] showed that in Nigeria, 71 percent of households have at least one mosquito net, 69 percent have at least one ITN, Thirty-six percent of households have at least one net for every two persons in the household, and 35 percent of households have an ITN or LLIN for the same indicator [4].

Most ITNs owned by caregivers were gotten free, either from the clinic or elsewhere outside the hospital. Only very few were bought from a chemist and the market. This brings to light the fact that there must have been an ITN distribution campaign around the study area. This is in consonance with studies done in Abia [47] and Abakaliki. [23] Mass distribution of ITN is a good strategy to improve malaria eradication from the country [38]. The is similar to the NMIS [4] where mosquito ITNs found in households were obtained through mass distribution campaigns (77\%), other sources of nets in Nigeria include immunisation visits (7\%); shops, supermarkets, open markets, or hawkers (6\%); and antenatal visits (5\%).

Over a third had used their ITNs for up to a year and majority of the children use ITN every night and all year round. This is a good practice to reduce the burden of malaria and need to be promoted. This is comparable to findings in studies done in Ghana [5] and Abia [47]. In a study done in a rural community in Enugu [41] only 12\% sleep under the ITN every night.

From this study, $71 \%$ and $69 \%$ of the caregivers use their ITN every night and all year round respectively while $26 \%$ use their nets during rainy season only. Seasonal variations in ITN use have been recorded, with ITN use increasing from $15 \%$ during the dry season to $56 \%$ during the rainy season in a study in 
Niger Republic [54]. In another survey in Sri Lanka, 75\% ITN use was recorded during dry season compared to $90 \%$ during rainy season.

Strangely, there are a few off label use of their ITNs like use to cover seedlings and use as fishing nets. Similar reports have been obtained in other parts of Africa; in a particular study in villages along Lake Victoria, ITNs were used by the indigenes for fishing instead of protection against malaria [55]. This finding is a common experience for household items and commodities. This off label use should be discouraged among care givers, since it deprived the children from sleeping under the nets.

Factors affecting the use of ITNs, Education was associated with a higher proportion of care givers with tertiary education use ITN. This is finding is similar to a study done in Enugu [41]. This finding is understandable as caregivers with tertiary education are more likely to understand the need to prevent Malaria and protect their children from mosquitoes.

More care givers with children within the age 1 - 3 years used ITN, than other age groups, A significant driver to ITN use was number of under-fives in household with use of ITN highest (47.9\%) in households with 2 under-fives. This relationship was reported in South Nigeria [56] where the highest ITN use rate among children in households with two or less children under five years who may be sleeping on the same bed with their parents. Another study in Lagos [37] stated that ITN use was highest in households with three or less children accounting for $63.8 \%$ in that study. This is because lower age groups are still tender and more prone to malaria even though all age groups are prone to malaria infection; caregivers with much younger children face a higher morbidity and mortality, thus the need to ensure compliance. Majority of caregivers who perceived ITN as a means of Malaria prevention used ITNs used ITNs. This demonstrates the importance of perception in adoption of the right behaviour for favourable health outcomes.

Nine out of ten caregivers were willing to buy ITN and also to recommend same to other mothers.In a study done in Ethiopia [53] (68.5\%) were willing to buy ITNs if available in the market while in a multi state study, [52] 27.1\% of respondents were willing to buy ITN in Akwa Ibom, [52] 67.9\% in Kebbi, [52] $61.3 \%$ in Nasarawa [52]. Half preferred to buy ITN over other things when confronted with an option to choose. More caregivers who were traders and civil servants were willing to buy ITN than farmer. This finding could be attributable to the fact that traders and civil servants may have more cash available for purchasing the ITNs when compared to farmers. Thus, farmers and unemployed caregivers will need to be empowered to make cash available to them. They should also be the focus for mass distribution campaigns for ITNs across the country.

More caregivers with tertiary education were willing to buy ITN, more when compared those with primary school education. This finding may be attributable to the fact that those with education may be well employed or engaged in trading 
and would be willing to buy ITNs. Also, their level of education will give them an edge in making the right decision based on facts on the importance of Insecticide treated nets.

Caregivers with children $1-3$ months old, of were willing to buy ITNs than those with children $22-24$ months. This stands to reason as caregivers perceive infants and 3 month old are still fragile and have a higher risk of dying of malaria. This age group may not be able to cope with Malaria, while the older ones may not be too bothered in error. This practice should not be encouraged as Malaria is a huge risk for all children.

\section{Conclusions}

A high proportion (89.3\%) of the children of caregivers use ITNs and over three quarters slept under ITN the night before the interview. And majority use it every night.

Caregivers do not use ITNs because they feel that ITNs are suffocating, have an unpleasant smell, inconveniencing, felt it is not necessary and because their mother did not use it.

Nine in ten owned ITNs, two third got the ITNs for free from outside the hospital, the hospital and family and friends and while a quarter paid for it in the market and chemist.

A few caregivers used ITNs for fishing and covering for seedlings.

Tertiary education, having much younger children (less than 3 years) and perception as a means of malaria prevention were associated with higher use of ITNs.

Nine in ten $\mathrm{f}$ the caregivers were willing to buy ITN and also recommend ITN to others

Caregivers who were traders and civil servants were willing to buy ITN than farmers. Tertiary education, having children $1-3$ months old, and owning 3 or more ITNs was associated with willingness to buy ITNs.

\section{Recommendation}

\section{To the Government \& Health Care Workers}

The Government and Health care workers should continue to encourage the Caregivers to keep using ITNs for their children.

ITNs should be impregnated with sweet smelling fragrances to reduce the unpleasant smells causing some caregiver to avoid its use.

More enlightenment needs to the carried for caregiver who still feel it is unnecessary to use ITNs. Older women and grandmothers can be used as ITN champions to help encourage caregivers to use ITNs especially for caregivers who felt their mothers did not use ITNs in their time.

Most caregivers got ITNs for free, thus it is important for Government and NGOs to continue and sustain the free distribution of ITNs to pregnant women for their children. 
Continuous reinforcement of messages on ITN use as a means of malaria prevention is necessary. Though only $1.6 \%$ of caregivers used ITNs for other things like cover for seedlings, fishing and screen at backyard, the general public should be educated by the government or/and health workers on proper use of ITN.

Unemployed caregivers, farmers who may not be able to afford ITNs should be targeted for free ITN distribution to improve ownership and utilization of ITNs.

\section{To caregivers}

Caregivers should not use ITNs for other things outside letting their children sleep under the ITN. Caregivers should continue to sustain the behavioural change by using the ITNs for their children.

\section{Conflicts of Interest}

The authors declare no conflicts of interest regarding the publication of this paper.

\section{References}

[1] Tizifa, T.A., Kabaghe, A.N., McCann, R.S., van den Berg, H., Van Vugt, M. and Phiri, M.S. (2018) Prevention Efforts for Malaria. Current Tropical Medicine Reports, 5, 41-50. https://doi.org/10.1007/s40475-018-0133-y

[2] World Health Organization (2018) World Malaria Report 2018. World Health Organization, Geneva.

[3] World Health Organization (2017) Insecticide-Treated Mosquito Net: A WHO Position Statement. World Health Organization, Geneva.

[4] National Malaria Elimination Programme (NMEP), National Population Commission (NPopC), National Bureau of Statistics (NBS) and II (2016) Nigeria Malaria Indicator Survey 2015. Abuja, Nigeria, and Rockville, MD.

[5] Manu, G., Boamah-Kaali, E.A., Febir, L.G., Ayipah, E., Owusu-Agyei, S. and Asante, K.P. (2017) Low Utilization of Insecticide-Treated Bed Net among Pregnant Women in the Middle Belt of Ghana. Malaria Research and Treatment, 2017, 2-12. https://doi.org/10.1155/2017/7481210

[6] World Health Organization (2016) World Malaria Report. The Report Gives Great Highlights of the Current Malaria Burden and Situation in Malaria Prevention and Control.

[7] World Health Organization (2016) World Malaria Terminology: Global Malaria Programme. World Health Organization, Geneva.

[8] National Population Commission (NPC) [Nigeria] and ICF (2019) Nigeria Demographic and Health Survey 2018. Abuja, Nigeria, and Rockville, MD.

[9] Nanvyat, N., Mulambalah, C.S., Ajiji, J.A., Dakul, D.A. and Tsingalia, M.H. (2017) Prevalence of Human Malaria Infection and Its Transmission Pattern in the Highlands and Lowlands of Plateau State, Nigeria. Indian Journal of Science and Technology, 10, 1-9. https://doi.org/10.17485/ijst/2017/v10i32/113622

[10] USAID (2018) US Presidents Malaria Initiative: Malaria Operational Plan FY 2018.

[11] Francesco, R. (2012) Social Implications of Malaria and Their Relationships with Poverty. Mediterranean Journal of Hematology and Infectious Diseases, 4, e2012048. 
https://doi.org/10.4084/mjhid.2012.048

[12] Kolawole, O.T. and Stephen, A.O. (2016) Mothers' Socioeconomic Differentials and Management of Malaria in Nigeria. Sage Open, 2016, 1-9.

[13] Onwujekwe, O., Hanson, K. and Fox Rushby, J. (2004) Inequalities in Purchase of Mosquito Nets and Willingness to Pay for Insecticide-Treated Nets in Nigeria: Challenges for Malaria Control Interventions. Malaria Journal, 3, 1-8.

[14] WHO (2017) Global Malaria Program. Achieving and Maintaining Universal Coverage with Long-Lasting Insecticidal Nets for Malaria Control.

[15] Onwujekwe, O., Hanson, K., Uzochukwu, B., Ichoku, H., Ike, E. and Onwughalu, B. (2010) Are Malaria Treatment Expenditures Catastrophic to Different Socio-Economic and Geographic Groups and How Do They Cope with Payment? A Study in Southeast Nigeria. Tropical Medicine \& International Health, 15, 18-25. https://doi.org/10.1111/j.1365-3156.2009.02418.x

[16] Lindsay, S.W., Snow, R.W., Broomfield, G.L., Janneh, M.S., Wirtz, R.A. and Greenwood, B.M. (1989) Impact of Permethrin-Treated Bednets on Malaria Transmission by the Anopheles Gambiae Complex in The Gambia. Medical and Veterinary Entomology, 3, 263-271. https://doi.org/10.1111/j.1365-2915.1989.tb00226.x

[17] National Bureau of Statistics (NBS) and United Nations Children's Fund (UNICEF) (2018) 2018 National Nutrition and Health Survey, Report. NBS and UNICEF, Abuja, Nigeria.

[18] Esimai, O.A. and Aluko, O.O. (2015) Determinants of Use of Insecticide Treated Bednets Among Caregivers of Under Five Children in an Urban Local Government Area of Osun State, South-Western Nigeria. Global Journal of Health Science, 7, 20-27. https://doi.org/10.5539/gjhs.v7n2p20

[19] Ovadje, L. and Nriagu, J. (2016) Multi-Dimensional Knowledge of Malaria among Nigerian Caregivers: Implications for Insecticide Treated Net Use by Children. Malaria Journal, 15, 516. https://doi.org/10.1186/s12936-016-1557-2

[20] World Health Organization (2007) Insecticide-Treated Mosquito Net: A WHO Position Statement. World Health Organization, Geneva.

[21] World Health Organization (2007) Global Malaria Programme. Malaria Elimination: A Field Manual for Low and Moderate Endemic Countries.

[22] Sina, O.J. (2018) An Assessment of the use of Insecticide Treated Net among under Five in Ekiti State as a Means of Prevention of Malaria. Perceptions in Reproductive Medicine, 2, 149-156.

[23] Orji, M.L., Onyire, N.B., Chapp-Jumbo, A. and Anyanwu, O.U. (2018) Perception and Utilization of Insecticide-Treated Mosquito Net among Caregivers of Children in Abakaliki, Nigeria. Annals of African Medicine, 17, 172-177. https://doi.org/10.4103/aam.aam_64_16

[24] Zegers de Beyl, C., Koenker, H., Acosta, A., Onyefunafoa, E.O., Adegbe, E. and McCartney-Melstad, A. (2016) Multi-Country Comparison of Delivery Strategies for Mass Campaigns to Achieve Universal Coverage with Insecticide-Treated Nets: What Works Best? Malaria Journal, 15, 58. https://doi.org/10.1186/s12936-016-1108-x

[25] Wiseman, V., Scott, A., McElroy, B., Conteh, L. and Steven, W. (2007) Determinants of Bed Net Use in Gambia; Implication for Malaria Control. The American Journal of Tropical Medicine and Hygiene, 76, 830-836. https://doi.org/10.4269/ajtmh.2007.76.830

[26] Gabresilassie, F.E. and Miriam, D.H. (2011) Factors Influencing People's Willingness to Buy Insecticide-Treated Bednets in Abraminch Zuria District, Southern 
Ethiopia. Journal of Health, Population and Nutrition, 29, 200-206. https://doi.org/10.3329/jhpn.v29i3.7867

[27] Ahmed Ali, B.H. (2008) Assessment of Insecticide Treated Nets Coverage for Malaria Control in Kafta-Humera District, Tigray: Possession versus Use by High Risk Groups. Ethiopian Journal of Health Development, 22, 260-278.

[28] Runsewe-Abiodun, I. and Alabi, D.A. (2014) Ownership of Bed Nets and use by Children below 5 Years in Sagamu Local Government Area of Ogun State, Nigeria. International Journal of Tropical Disease and Health, 4, 1001-1010. https://doi.org/10.9734/IJTDH/2014/12143

[29] Runsewe-Abiodun, I., Iyabo, T. and Runsewe, O.O. (2013) Attitude and Practice of Pregnant Women to Use of Insecticide Treated Nets in South-West Nigeria. African Journal of Gender and Women Studies, 3, 202-210.

[30] Oresanya, O.B., Hoshen, M. and Sofola, O.T. (2008) Utilization of InsecticideTreated Nets by under-Five Children in Nigeria: Assessing Progress towards the Abuja Targets. Malaria Journal, 7, 145. https://doi.org/10.1186/1475-2875-7-145

[31] Paulander, J., Olsson, H., Lemma, H., Getachew, A. and San Sebastian, M. (2009) Knowledge, Attitudes and Practice about Malaria in Rural Tigray, Ethiopia. Global Health Action, 2, 1-7. https://doi.org/10.3402/gha.v2i0.1839

[32] Pryce, J., Richardson, M. and Lengeler, C. (2019) Insecticide-Treated Nets for Preventing Malaria (Review). Cochrane Database of Systematic Reviews, 11, CD000363. http://www.cochranelibrary.com https://doi.org/10.1002/14651858.CD000363.pub3

[33] Cochrain, G. (1977) Sampling Techniques. 2nd Edition, John Willey and Sons Inc., New York.

[34] Iloh, G.U.P., Amadi, A.N., Obiukwu, C.E., Njoku, P.U., Ofoedu, J.N. and Okafor, G.O.C. (2013) Family Biosocial Variables Influencing the Use of Insecticide Treated Nets for Children in Eastern Nigeria. Journal of Family and Community Medicine, 20, 12-19. https://doi.org/10.4103/2230-8229.108178

[35] Iwuafor, A.A., Egwuatu, C.C., Nnachi, A.U., et al. (2016) Malaria Parasitaemia and the Use of Insecticide-Treated Nets (INTs) for Malaria Control amongst under-5 Year Old Children in Calabar, Nigeria. BMC Infectious Diseases, 16, 1-12. https://doi.org/10.1186/s12879-016-1459-5

[36] Jones, C., Bruce, J. and Mshinda, H. (2010) Household Ownership and Use of Insecticide Treated Nets among Target Groups after Implementation of a National Voucher Programme in the United Republic of Tanzania: Plausibility Study Using Three Annual Cross Sectional Household Surveys. British Medical Journal, 338, Article ID: 24434.

[37] Okafor, I.P. and Odeyemi, K.A. (2012) Use of Insecticide-Treated Mosquito Nets for Children under Five Years in an Urban Area of Lagos State, Nigeria. Nigerian Journal of Clinical Practice, 15, 1-4. https://doi.org/10.4103/1119-3077.97325

[38] Adewole, A., Faparusi, F. and Alli, F.F. (2011) Does Free Distribution of ITN Affect Its Usage? A Survey among Mothers/Caregivers in Ilaro Ogun State, Nigeria. South East Asia Journal of Public Health, 1, 71-72. https://doi.org/10.3329/seajph.v1i1.13226

[39] Taremwa, I.M., Ashaba, S., Adrama, H.O., et al. (2017) Knowledge, Attitude and Behaviour towards the Use of Insecticide Treated Mosquito Nets among Pregnant Women and Children in Rural Southwestern Uganda. BMC Public Health, 17, 4-11. https://doi.org/10.1186/s12889-017-4824-4

[40] Nyavor, K.D., Kweku, M., Agbemafle, I., Takramah, W., Norman, I. and Tarkang, 
E. (2017) Assessing the Ownership, Usage and Knowledge of Insecticide Treated Nets (ITNs) in Malaria Prevention in the Hohoe Municipality, Ghana. The Pan African Medical Journal, 8688, 1-8. https://doi.org/10.11604/pamj.2017.28.67.9934

[41] Uzoamaka, A.S., Onyemaechi, N.E., Samuel, O. and Ajogwu, R. (2016) Knowledge and Utilization of Insecticide Treated Nets in a Rural Community in International Journal of Health Sciences and Research Knowledge and Utilization of Insecticide Treated Nets in a Rural Community in Southeast Nigeria. International Journal of Health Sciences and Research, 6, 37-45.

[42] Edeli, B.O., Ikefuna, A.N., Emodi, J.I. and Adimora, G.N. (2010) Awareness and Use of Insecticide-Treated Bed Nets among Children Attending Outpatient Clinic at UNTH, Enugu: The Need for an Effective Mobilization Process. African Health Sciences, 10, 117-119.

[43] Konlan, K.D., Japiong, M., Konlan, K.D., Afaya, A., Salia, S.M. and Kombat, J.M. (2019) Utilization of Insecticide Treated Bed Nets (ITNs) among Caregivers of Children under Five Years in the Ho Municipality. Interdisciplinary Perspectives on Infectious Diseases, 2019, Article ID: 3693450. https://doi.org/10.1155/2019/3693450

[44] Alfonso, Y.N., Lynch, M., Mensah, E., Piccinini, D. and Bishai, D. (2020) Willingness to Pay for Long Lasting Insecticide Treated Bed Nets : A Discrete Choice Experiment with Real Payment in Ghana. Malaria Journal, 19, 1-13. https://doi.org/10.1186/s12936-019-3082-6

[45] Atieli, H.E., Zhou, G., Afrane, Y., Lee, M., Mwanzo, I. and Githeko, A.K. (2011) Insecticide-Treated Net (ITN) Ownership, Usage, and Malaria Transmission in the Highlands of Western Kenya. Parasites \& Vectors, 4, 113. https://doi.org/10.1186/1756-3305-4-113

[46] Adebayo, A.M., Akinyemi, O.O. and Cadmus, E.O. (2014) Ownership and Utilisation of Insecticide-Treated Mosquito Nets among Caregivers of under-Five Children and Pregnant Women in a Rural Community in Southwest Nigeria. Journal of Preventive Medicine and Hygiene, 55, 58-64.

[47] Ezeigbo, O.R., Ejike, E.N. and Nwachukwu, I. (2016) Insecticide-Treated Bed Net (ITN): Ownership and Usage in the Control of Malaria in Abia State, Nigeria. American Journal of Epidemiology and Infectious Disease, 4, 42-46.

[48] Iwashita, H., Gabriel, D., Kyoko, F., et al. (2010) Sleeping Arrangement and House Structure Affects Bed-Net Use in Villages along Lake Victoria. Malaria Journal, 9, 176. https://doi.org/10.1186/1475-2875-9-176

[49] Ukibe, S., Mbanugo, J., Ukibe, N. and Ikeakor, L. (2013) Level of Awareness and Use of Insecticide Treated Bed Nets among Pregnant Women Attending Antenatal Clinics in Anambra State, South East Nigeria. Journal of Public Health and Epidemiology, 5, 391-396.

[50] Zangypo, K., Zangypo, N. and Poulsen, K. (2011) A Study on Knowledge, Attitude and Practice about Malaria Awareness and Bed Net Use. Journal of Bhutan Studies, 135-146.

[51] Singh, M., Brown, G. and Rogerson, S.J. (2013) Ownership and Use of Insecticide-Treated Nets during Pregznancy in sub-Saharan Africa: A Review. Malaria Journal, 12, 268. https://doi.org/10.1186/1475-2875-12-268

[52] Babalola, S., Adedokun, S.T., Melstad, A.M., et al. (2018) Factors Associated with Caregivers' Consistency of Use of Bed Nets in Nigeria: A Multilevel Multinomial Analysis of Survey Data. Malaria Journal, 17, 1-13. https://doi.org/10.1186/s12936-018-2427-X 
[53] Adisu, A., Aleme, A., Girma, E. and Fentahun, N. (2014) Willingness to Pay for Insecticide Treated Nets in Berehet District, Amhara Region. Implication of Social Marketing, Northern Ethipia. https://doi.org/10.4314/ejhs.v24i1.10

[54] Thwing, J., Hochberg, N., Vanden Eng, J., Issifi, S., Eliades, M.J., Minkoulou, E., et al. (2008) Insecticide-Treated Net Ownership and Usage in Niger after a Nationwide Integrated Campaign. Tropical Medicine \& International Health, 13, 827-834. https://doi.org/10.1111/j.1365-3156.2008.02070.x

[55] Minakawa, N., Dida, G.O., Sonye, G.O., Futami, K. and Kaneko, S. (2008) Unforeseen Misuses of Bed Nets in Fishing Villages along Lake Victoria. Malaria Journal, 7, 165. https://doi.org/10.1186/1475-2875-7-165

[56] Ordinioha, B. (2007) The Use of Insecticide-Treated Bed Net in a Semi-Urban Community in South-South, Nigeria. Nigerian Journal of Medicine, 16, 223-226. 